\title{
Studi Alterasi Hidrotermal dan Mineralisasi Batuan di Sekitar Mata Air Panas Garara Bukit Kili, Kabupaten Solok, Sumatera Barat
}

\author{
Rahmat Ravvi Qodri", Ardian Putra \\ Laboratorium Fisika Bumi, Jurusan Fisika, \\ Fakultas Matematika dan Ilmu Pengetahuan Alam Universitas Andalas \\ Kampus Unand Limau Manis, Padang, 25163, Indonesia \\ *rahmatravvi.qodri.rrq@gmail.com
}

\begin{abstract}
ABSTRAK
Telah dilakukan penelitian mengenai studi alterasi hidrotermal dan mineralisasi pada batuan di sekitar mata air panas Garara (Bukit Kili), Kabupaten Solok, Sumatera Barat. Sampel batuan diambil pada tiga daerah stratigrafi penyusun daerah Bukit Kili, yaitu Lahar Bukit Bakar (Qulh), Lahar Gunung Talang (QTlh), dan Vulkanik Tua (TTI). Penentuan mineral alterasi yang terbentuk dilakukan dengan melakukan karakterisasi menggunakan X-ray Fluorescence (XRF), X-ray Diffractometer (XRD), dan Scanning Electron Microscopy (SEM). Hasil XRF menunjukkan bahwa batuan pada daerah penelitian merupakan batuan yang terbentuk dari aktivitas magma andesit yang berkaitan dengan zona subduksi pada pinggiran benua aktif dan dikontrol oleh aliran gas pada proses pengkayaan magma. Hasil XRD memperlihatkan adanya mineral albit, kristobalit, tridimit dan diopsid, tipe alterasi yang terbentuk pada daerah penelitian adalah tipe propilitik, dan silifikasi. Mikrotekstur pada batuan Lahar Gunung Talang (QTlh) memiliki tekstur bulat, kubus, dan prismatik yang tidak beraturan

Kata kunci: alterasi, andesit, Garara, propilitik, silifikasi, stratigrafi.
\end{abstract}

\section{ABSTRACT}

Characterises of hidrotermal alteration and mineralization of rock around Garara hot spring (Bukit Kili), Solok District, West Sumatera had been investigated. Samples ware taken from three stratigraphic regions of Bukit Kili, namely Lava of Bakar Hill (Qulh), Lava of Talang Mountain (QTlh), and Old Volcanic (TTI). Mineral alteration was characteried using X-ray Fluorescence (XRF), X-ray Diffractometer (XRD), and Scanning Electron Microscopy (SEM). XRF results show that the rocks in the study area are rocks created from activity of andesite magma related to subduction zones on the active continent periphery and controlled by gas flow in the magma enrichment process. The XRD results show the presence of minerals albit, cristobalite, trydimite and diopside. The type of alteration formed in the study area are propylitic type, and silification. The microtextures of rocks of Talang Mountain Lava (QTlh) have irregular round, cube and prismatic textures.

Keywords: alteration, andesite, Garara, propylitic, stratigraphy, silicification.

\section{PENDAHULUAN}

Kabupaten Solok berada pada struktur patahan aktif yang merupakan bagian dari Sesar Sumatera yang terbentuk akibat adanya interaksi konvergen antara lempeng Indo-Australia dengan lempeng Eurasia. Akibat lain dari pergerakan lempeng tersebut adalah terbentuknya jalur gunung api aktif yang menyebabkan terbentuknya potensi panas bumi yang dapat dimanfaatkan sebagai sumber energi yang terbarukan. Salah satu daerah potensi panas bumi di Kabupaten Solok terdapat di Bukit Kili.

Daerah Bukit Kili mempunyai delapan satuan batuan yang dapat dilihat pada Gambar 1, dengan urutan dari tua ke muda yaitu Satuan Batuan Malihan (TS), Satuan batuan Vulkanik Tua (TTI), Satuan Batuan Lava Bukit Kili (QKj), Satuan Batuan Lava Bukit Bakar (QBI), Satuan Batuan Lahar Bukit Bakar (QUlh), Satuan Batuan Lahar Gunung Talang (QTlh), Endapan Danau (Qad) dan Endapan permukaan (Qbi) (Kholid dan Marpaung, 2011). Pada daerah satuan batuan Lahar Bukit Bakar (QUlh) dan Lahar Gunung Talang (QTlh) ditemukan manifestasi permukaan berupa mata air panas. Manifestasi ini menujukkan adanya sumber panas yang akan mempengaruhi terjadinya proses hidrotermal pada satuan batuan yang ada di atasnya. Manifestasi terbentuk akibat adanya sistem hidrotermal, dimana terjadi sirkulasi larutan hidrotermal secara lateral dan vertikal pada temperatur dan tekanan yang berbeda (Pirajno, 1992). 


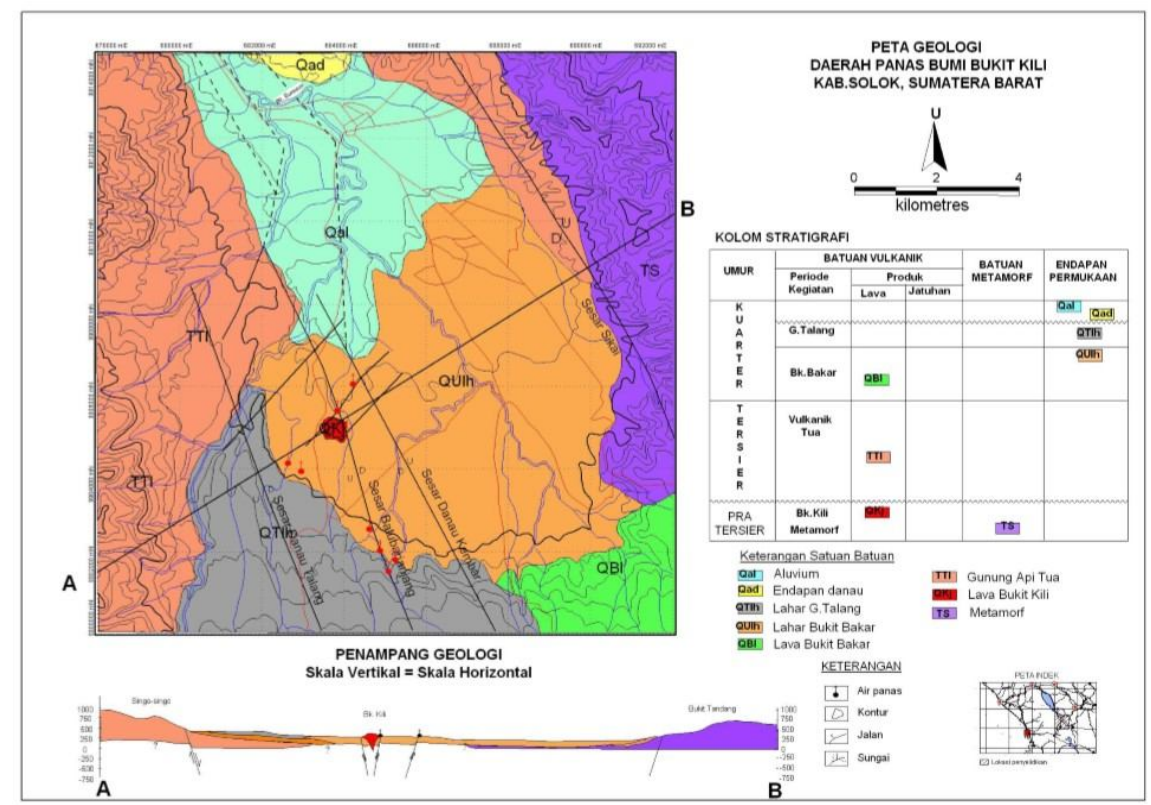

Gambar 1 Peta Geologi daerah Bukit Kili

Dengan adanya sirkulasi larutan hidrotermal ini mengakibatkan adanya interaksi antara larutan hidrotermal dengan batuan yang dilaluinya dan kemudian secara kimiawi akan membentuk mineral alterasi. Alterasi hidrotermal merupakan proses yang terjadi akibat adanya interaksi antara batuan asal dengan larutan hidrotermal. Interaksi antara larutan hidrotermal dan batuan yang dilewati akan mengubah sifat fisik dan kimia meliputi tekstur dan mineralogi (Corbett dan Leach, 1997). Proses alterasi hidrotermal merupakan suatu bentuk metasomatisme, yaitu pertukaran komponen kimiawi antara cairan-cairan dengan batuan dinding. Proses alterasi hidrotermal yang terjadi akibat adanya interaksi antara batuan dengan larutan hidrotermal dapat menyebabkan terjadinya penggantian mineral, pelarutan, dan pengendapan langsung mineral dari larutan yang mengisi rekahan atau pori batuan (Pirajno, 1992). Vandani, dkk., (2014) menyatakan bahwa dari mineral-mineral alterasi hidrotermal yang terbentuk dapat menjadi indikator dalam menentukan temperatur, permeabilitas, dan sifat fluida hidrotermal yang terdapat pada sumber mata air panas.

Inanda (2017) telah melakukan penelitian endapan sinter dari beberapa sumber mata air panas di daerah sekitar Gunung Talang, Kabupaten Solok. Endapan sinter yang diambil dari mata air panas Garara dan dikarakterisasi dengan menggunakan X-Ray Diffractometer (XRD), Scanning Electron Microscopy (SEM) dan Fourier Transform Infrared (FTIR) menunjukkan bahwa sinter silika memiliki fasa opal-CT dan tekstur yang mengindikasikan adanya sistem panas bumi yang berusia muda. Dengan ditemukannya mineral yang diidentifikasi sebagai sumber panas bumi di daerah Bukit Kili, maka akan dilakukan kajian tentang mineral alterasi yang terdapat pada batuan yang berada di sekitar mata air panas Garara yaitu di tiga formasi batuan penyusun daerah Bukit Kili yaitu, Lahar Bukit Bakar (QUlh), Lahar Gunung Talang (QTlh), dan Vulkanik Tua (TTI).

Tujuan dari penelitian ini adalah untuk menganalisasi karakteristik batuan yang mewakili satuan stratigrafi pada daerah Bukit Kili dan melihat ada atau tidaknya mineral alterasi yang terdapat pada daerah penelitian. Manfaat penelitian ini adalah untuk memberikan informasi tentang mineral alterasi yang terbentuk di daerah sekitar Bukit Kili, dan memberikan informasi tentang hubungan mineral alterasi dengan keadaan sistem panas bumi di daerah Bukit Kili.

\section{METODE}

\subsection{Pengambilan sampel}

Sampel batuan yang diambil merupakan sampel batuan yang mewakili stratigrafi penyusun Bukit Kili. Sampel batuan yang diambil merupakan batuan yang dominan terdapat 
pada daerah tersebut. Lokasi pengambilan sampel dipilih berdasarkan stratigrafi daerah Bukit Kili yaitu: Satuan Lahar Bukit Bakar (Qulh), satuan Lahar Gunung Talang (QTlh), Satuan Vulkanik Tua (TTI). Sampel diambil menggunakan martil dan pahat, masing masing satuan stratigrafi diambil satu sampel batuan.

\subsection{Preparasi Sampel}

Proses preparasi sampel adalah sebagai berikut:

1. Bongkahan batuan dari diambil berdasarkan satuan stratigrafi di hancurkan menggunakan martil menjadi bagian yang lebih kecil

2. Serpihan batuan tersebut kemudian dihaluskan dengan menggunakan alu dan lumpang menjadi serbuk yang lebih halus.

3. Serbuk disaring dengan menggunakan ayakan 100 mesh agar diperoleh ukuran bulir yang lebih kecil untuk pengujian dengan XRD, XRF, dan SEM.

\subsection{Pengujian Sampel}

\subsubsection{Kandungan Mineral}

XRF digunakan untuk mengetahui komposisi dan konsentrasi unsur unsur yang terkandung. XRF yang digunakan bermerk XRF Panalytical Epsilon 3. Data keluaran dari karakteristik XRF ini berupa mineral yang terkandung di dalam sampel dan persentase dari jumlah mineral tersebut.

\subsubsection{Struktur Batuan Penyusun Stratigrafi Bukit Kili}

Untuk mengetahui fasa dari mineral yang terkandung pada batuan akan dilakukan dengan menggunakan XRD. Sampel dianalisis dengan metode difraksi sinar-X menggunakan monokromator grafit radiasi $\mathrm{Cu}-\mathrm{K} \alpha$. XRD yang digunakan bermerk PanAnalytical tipe Expert Pro. Peralatan XRD ini dilengkapi dengan software high scrore plus dan PDF2. Data keluaran dari XRD berupa grafik hubungan antara intensitas dengan sudut 2 $\theta$. Data pengukuran XRD ini akan dibandingkan dengan data ICDD (International Centre for Diffraction Data). Dari hasil perbandingan data XRD dengan data ICCD akan dapat memberikan informasi mengenai struktur dan fasa batuan.

\subsubsection{Tekstur Batuan}

Pengamatan tekstur mikro pada sampel diidentifikasi menggunakan SEM. Pengujian dengan SEM dilakukan di Laboratorium SEM Pusat Penelitian dan Pengembangan Geologi Kelautan (PPPGL) Bandung. Pembesaran yang digunakan pada karakterisasi sem ini adalah 10.000x, dan 20.0000x. Data keluaran dari pengujian SEM ini berupa gambar dari sampel. Dimana dari gambar tersebut dapat dilihat ukuran dan bentuk dari partikel dari unsur tersebut.

\section{HASIL DAN DISKUSI}

\subsection{Kandungan Mineral}

Analisis menggunakan XRF menghasilkan komposisi mineral utama pada sampel, seperti $\mathrm{SiO}_{2}, \mathrm{Al}_{2} \mathrm{O}_{3}, \mathrm{CaO}, \mathrm{MgO}, \mathrm{Fe}_{2} \mathrm{O}_{3}, \mathrm{~K}_{2} \mathrm{O}, \mathrm{P}_{2} \mathrm{O}_{5}$. Kandungan mineral pada sampel Batuan Stratigrafi Lahar Bukit Bakar, Lahar Gunung Talang, dan Vulkanik Tua dengan mengggunakan pada Tabel 1. Stratigrafi daerah Bukit Kili disusun oleh batuan yang merupakan hasil produksi dari erupsi Gunung Talang, Bukit Bakar, dan dari batuan vulkanik tua. Hal ini sesuai dengan kandungan mineral pada sampel dimana ditemukan mineral $\mathrm{SiO}_{2}$ sebesar 60,097\% - 61,905\%. Produk batuan yang dihasilkan merupakan batuan yang berasal dari aliran piroklastik dan batuan yang terbentuk dari aliran lava (Munandar, dkk 2003).

Pada sampel dari ketiga titik tersebut juga ditemukan mineral $\mathrm{K}_{2} \mathrm{O}$ sebesar $1,668 \%$ $2,256 \%$. Dengan perbandingan mineral-mineral ini, tipe magma yang membentuk batuan pada lokasi penelitian merupakan magma andesit dengan kadar unsur kalium sedang yang bersifat intermediet (Le Meitre, 2002). Batuan andesit memiliki nilai densitas yang tinggi dengan nilai densitas berkisar antara 2,4-2,8 $\mathrm{g} / \mathrm{cm}^{3}$, dengan tingginya nilai densitas batuan andesit ini mengakibatkan nilai porositas batuannya kecil sehingga nilai permeabilitas pada batuan juga 
kecil. Kecilnya nilai porositas dan permeabilitas batuan, daerah penelitian diperkirakan merupakan daerah batuan penudung (caprock). Batuan penudung merupakan lapisan batuan yang berfungsi untuk sebagai penghalang uap panas yang terakumulasi dalam lapisan batuan reservoir agar tidak keluar ke permukaan (Dipipo, 2008).

Tabel 1 Analisis geokimia mineral utama batuan penyusun stratigrafi daerah sekitar Bukit

\begin{tabular}{cccc}
\multicolumn{3}{c}{ Kili } \\
\hline \multirow{2}{*}{ Mineral } & $\begin{array}{c}\text { Lahar Bukit } \\
\text { Bakar (Qulh) }\end{array}$ & $\begin{array}{c}\text { Lahar Gunung } \\
\text { Talang (QTlh) }\end{array}$ & $\begin{array}{c}\text { Vulkanik } \\
\text { Tua (TTI) }\end{array}$ \\
\hline $\mathrm{SiO}_{2}$ & $60,09 \%$ & $61,65 \%$ & $61,90 \%$ \\
$\mathrm{Al}_{2} \mathrm{O}_{3}$ & $18,64 \%$ & $20,65 \%$ & $18,55 \%$ \\
$\mathrm{CaO}$ & $8,114 \%$ & $6,081 \%$ & $8.097 \%$ \\
$\mathrm{MgO}$ & $4,039 \%$ & $2,245 \%$ & $2,653 \%$ \\
$\mathrm{Fe}_{2} \mathrm{O}_{3}$ & $5,43 \%$ & $5,069 \%$ & $5,066 \%$ \\
$\mathrm{~K}_{2} \mathrm{O}$ & $1,668 \%$ & $1,804 \%$ & $2,256 \%$ \\
$\mathrm{P}_{2} \mathrm{O}_{5}$ & $1,224 \%$ & $0,724 \%$ & $0,52 \%$ \\
\hline
\end{tabular}

Selain itu, juga ditemukan mineral alumina $\left(\mathrm{Al}_{2} \mathrm{O}_{3}\right)$ sebesar $18,55 \%$ - 20,651\%. Kandungan $\mathrm{Al}_{2} \mathrm{O}_{3}$ dan $\mathrm{K}_{2} \mathrm{O}$ yang tinggi ini menunjukkan bahwa ciri kimia mineral utama pembentuk batuan seperti mineral feldspar, mika dan lempung (iliit) yang kaya akan $\mathrm{Al}_{2} \mathrm{O}_{3}$ dan $\mathrm{K}_{2} \mathrm{O}$ masih tetap bertahan (Harahap, 2010). Kandungan unsur-unsur ini, secara umum, terutama yang immobile ( $\mathrm{Ti}, \mathrm{Mg}$, dan $\mathrm{Fe}$ ) menunjukkan bahwa batuan tersebut berasal dari aktivitas magma. Pola geokimia sampel batuan yang diambil pada daerah penelitian dicirikan oleh $\mathrm{Al}_{2} \mathrm{O}_{3}$ yang tinggi, kandungan $\mathrm{MgO}$ yang redah (2-5\%), kandungan alkali $\left(\mathrm{Na}_{2} \mathrm{O}+\mathrm{K}_{2} \mathrm{O}\right)$ yang kurang dari $8 \%$, dan kandungan $\mathrm{TiO}_{2}$ yang kurang dari satu persen menujukkan karakteristik magma yang membentuk batuan pada daerah penelitian merupakan magma yang berkaitan dengan subduksi pada pinggiran benua aktif (Harahap, 2010).

Mineral logam dasar lainnya yang ditemukan adalah tembaga $(\mathrm{Cu})$, timbal $(\mathrm{Pb})$, seng (Zn), dan Alumunium (Al). Akumulasi logam-logam tersebut terbentuk melalui proses hidrotemal. Selain itu juga ditemukan unsur-unsur $\mathrm{P}, \mathrm{S}, \mathrm{Cl}, \mathrm{Mn}, \mathrm{Fe}, \mathrm{Cu}, \mathrm{Zn}, \mathrm{As}, \mathrm{Ag}$, dan Pb. Dengan ditemukan unsur-unsur tersebut menyatakan bahwa faktor yang mengontrol proses mineralisasi pada daerah penelitian adalah oleh aliran gas pada proses pengkayaan magma (Lindgren, 1933).

\subsection{Struktur Batuan penyusun Stratigrafi Bukit Kili}

Struktur batuan penyusun stratigrafi Bukit Kili dapat diketahui dengan karakterisasi sinter menggunakan XRD. Sampel batuan yang dikarakterisasi adalah sampel batuan yang diambil pada daerah stratigrafi Lahar Gunung Talang, karena hasil XRF menunujukan mineral yang ditemukan pada ketiga daerah stratigrafi tersebut sama.

Gambar 2 memperlihatkan difraktogram sampel batuan daerah stratigrafi Lahar Gunung Talang (QTlh), dan dapat dilihat bahwa pada sampel batuan ini didominasi oleh mineral albit, tridimit, kristobalit, dan diopsid. Berdasar data ICDD 01-072-1246, albit yang terdapat pada sampel memiliki struktur kristal berupa anorthic, dengan nilai $a=8,1490 \AA$, $b=12,88 \AA, c=$ $7,1060 \AA, \alpha=93,37^{\circ}, \beta=116,3^{\circ}, \gamma=90,28^{\circ}$. Dari parameter kristal pada data ICDD ini albit pada sampel merupakan high albit. Albit merupakan mineral primer bagian dari mineral kelompok plagioklas. Menurut Reaksi Bowen albit terbentuk dari proses pendinginan magma yang terbentuk pada rentang suhu antara $750-800^{\circ} \mathrm{C}$. Albit merupakan mineral alterasi yang terbentuk pada batuan beku. Albit terbentuk dari proses albitisasi yang merupakan proses dimana terjadi penggantian antara unsur $\mathrm{Ca}$ dengan $\mathrm{Na}$.

Berdasarkan data ICDD 01-075-0923, mineral tridimit merupakan fasa dari mineral silika $\left(\mathrm{SiO}_{2}\right)$. Tridimit yang ditemukan pada sampel memiliki struktur kristal anorthic/triclinic, dengan nilai $a=9,932 \AA, b=17,216 \AA, c=81,864 \AA, \alpha=90^{\circ}, \beta=90^{\circ}, \gamma=90^{\circ}$. Dari struktur kristal, tridimit yang terbentuk pada sampel merupakan $\alpha$-tridimit. Dari diagram fasa silika diketahui pembentukan mineral tridimit terbentuk pada suhu $870-1470^{\circ} \mathrm{C}$. Selain tridimit juga ditemukan kristobalit yang juga merupakan fasa dari mineral silika. 


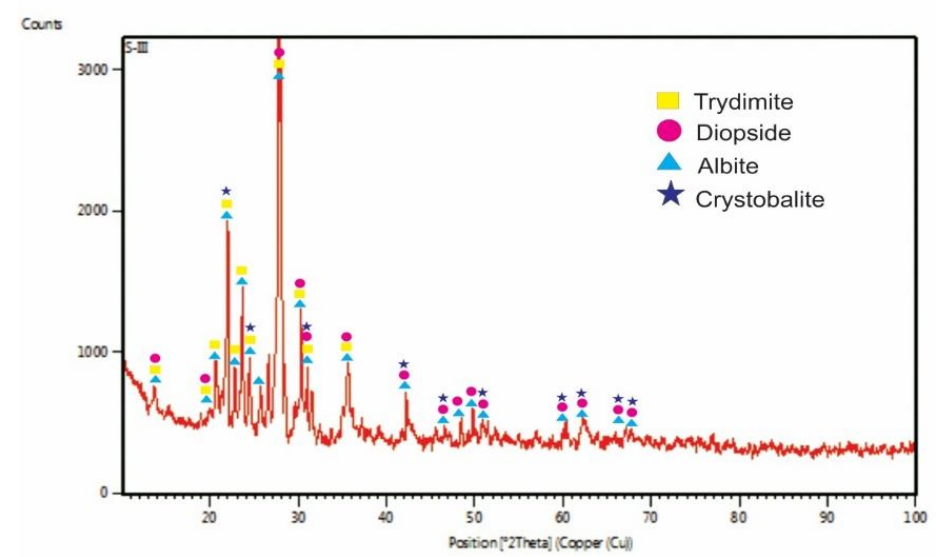

Gambar 2 Pola XRD sampel Batuan daerah stratigrafi Lahar Gunung Talang (QTlh)

Kristobalit yang ditemukan pada sampel memiliki struktur kristal tetragonal, dengan nilai $a=4,9640 \AA, b=4,9640 \AA, c=6,92 \AA, \alpha=90^{\circ}, \beta=90^{\circ}, \gamma=90^{\circ}$ sesuai dengan data ICDD 01-075-0923. Fasa silika kristobalit terbentuk pada suhu $1470-1705^{\circ} \mathrm{C}$. Dari struktur kristal kristobalit yang ditemukan pada sampel merupakan $\alpha$-kristobalit. Diopsid juga ditemukan pada sampel, berdasarkan data ICDD 01-083-1817 diopside yang ditemukan pada sampel memiliki sistem kristal monoclinic dengan nilai $a=9,7456 \AA, b=8,9198 \AA, c=5,2516 \AA, \alpha=90^{\circ}, \beta=$ $105,86^{\circ}, \gamma=90^{\circ}$.

Hasil XRD pada sampel satuan Lahar Gunung Talang (QTlh) menunjukkan adanya kehadiran mineral sekunder berupa silika (tridimit dan kristobalit). Pada sistem panas bumi mineral tridimit dan kristobalit berperan sebagai mineral yang menjadi penanda zona batuan penudung (Fitriany, 2015). Selain itu albit pada sampel menujukan bahwa tipe alterasi pada lokasi penelitian merupakan alterasi propilitik (Thompson dan Thompson, 1996). Guilbert dan Park (1986) menyatakan alterasi propilitik terbentuk pada temperatur $200-300^{\circ} \mathrm{C}$ dengan $\mathrm{pH}$ mendekati netral, dan pembentukan mineral ini terbentuk pada daerah dengan permeabilitas rendah.

Selain propilitik, tipe alterasi silifikasi juga ditemukan pada sampel yang ditandai dengan terbentuknya kristobalit, dan tridimit (Thompson dan Thompson 1996). Suteja, dkk (2016) menemukan alterasi silifikasi pada daerah Gunung Buleud yang terbentuk akibat pengayaan mineral silika berupa kristobalit dan mineral kuarsa dan terbentuk pada litologi andesit, diketahui bahwa pembentukan zona ini berkisar antara temperatur $100-200^{\circ} \mathrm{C}$. Selain itu, Fitriany, (2015) juga menemukan mineral tridimite dan kristobalit pada kelompok manifestasi Rinke, dan diperkirakan temperatur pembentukan mineral ini berkisar antara 100$160^{\circ} \mathrm{C}$. Berdasarkan data tersebut suhu pembentukan mineral alterasi silifikasi pada mata air panas Garara dan satuan batuan Lahar Gunung Talang diperkirakan berkisar antara $100-200^{\circ} \mathrm{C}$.

Dengan ditemukan $\alpha$-kristobalit dan $\alpha$-tridimit pada sampel batuan Lahar Gunung Talang dan mata air Panas Garara, maka opal yang terbentuk adalah opal-CT. Lynne dan Campbell (2003) memperlihatkan bahwa opal-CT yang terdapat di Umukuri, TVZ (Taupo Volcanic Zone) memiliki usia 40.000 tahun. Berdasarkan data petrologi departemen geologi Universitas Auckland, opal-CT yang dihasilkan oleh sinter silika di Umukuri memiliki usia 40.000-120.000 tahun (Campbell dkk., 2004). Berdasarkan data ini, satuan batuan Lahar Gunung Talang (QTlh) dan endapan sinter silika pada mata air panas Garara telah berusia dalam orde puluhan ribu tahun.

\subsection{Tekstur Batuan}

Karakterisasi menggunakan SEM bertujuan untuk mengetahui tekstur sinter silika pada sampel batuan. Sampel batuan yang diuji adalah sampel batuan yang diambil pada daerah stratigrafi Lahar Gunung Talang (QTlh). Pembesaran yang digunakan adalah 10.000x, dan 20.000x. 


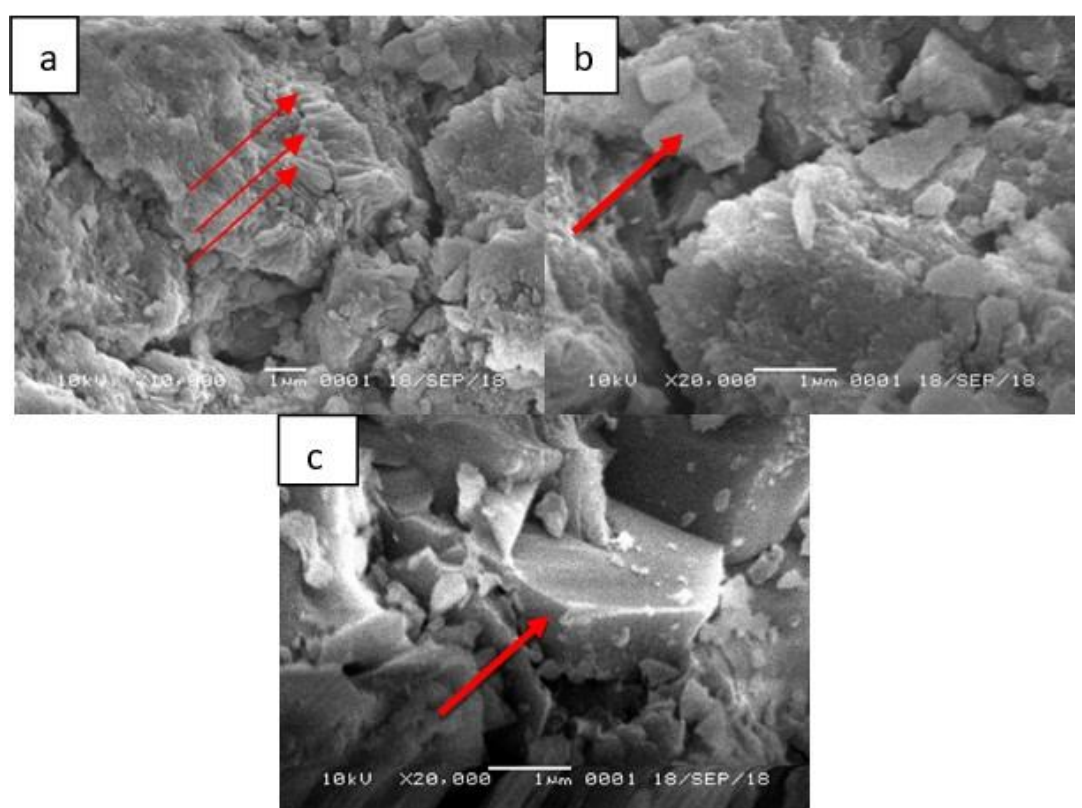

Gambar 3 (a).Hasil karakterisasi SEM sampel QTlh dengan pembesaran 10.000x, (b). Hasil Karakterisasi SEM sampel QTlh dengan pembesaran 20.000x, (c) hasil karakterisasi SEM sampel QTlh dengan pembesarn 20.000x

Hasil uji SEM pada Gambar 3 (a) memperlihatkan struktur mikro dari sampel batuan memiliki tekstur yang tidak beraturan dengan bentuk bulat yang ditunjukan oleh tanda panah. Henwood., dkk (2017) memperlihatkan bentuk tekstur bulat pada endapan partikel silika di daerah mata air panas Geyser Valley, Wairekai. Pada Gambar 3(b) juga terlihat struktur mikro yang tidak beraturan, tetapi dapat dilihat terdapat bentuk yang berbentuk kubus seperti yang ditunjuk oleh tanda panah.

Pada Gambar 3 (c) yang diambil pada posisi yang berbeda dapat dilihat bentuk pada batuan sampel berbentuk prisma yang ditunujukan oleh tanda panah. Horwell dkk. (2013) juga menemukan kristobalit dengan bentuk kristal prisma yang terbentuk pada kubah vulkanik Gunung Soufriere. Bentuk prismatik ini akan terbentuk pada pori-pori batuan, hal ini akan mengurangi permeabilitas pada batuan.

Perbedaan bentuk dari silika, tridimit, dan kristobalit yang berbeda menunjukan bahwa perubahan fasa pada silika akan mengubah bentuk kristal dari mineral tersebut. Perubahan tekstur ini berlangsung lama, perubahan ini akan ditunjukkan oleh penurunan porositas dan peningkatan kepadatan kristal (Herdianita,2000). Lynne dan Campbell (2003) menyatakan tekstur bulat membentuk tekstur permukaan yang halus dan peningkatan kepadatan pada batuan. Howell., dkk (2013) menyatakan bentuk prismatik dan kotak akan terbentuk pada pori-pori batuan hal ini akan mengurangi permeabilitas dan porositas pada batuan.

\section{KESIMPULAN}

Batuan yang terdapat pada daerah penelitian merupakan batuan yang terbentuk dari aktivitas magma andesit yang berkaitan dengan daerah subduksi pada pinggiran benua aktif. Tipe alterasi yang terbentuk pada daerah satuan Lahar Gunung Talang adalah propilitik yang ditandai dengan ditemukan mineral albit, dan tipe silifikasi yang ditandai dengan ditemukan $\alpha-$ kristobalit, dan $\alpha$-tridimit.dan opal yang terbentuk adalah opal-CT yang berusia puluhan ribu tahun. Bentuk kristal pada batuan Lahar Gunung Talang berbentuk bulat lonjong, kubus dan prismatik.

\section{DAFTAR PUSTAKA}

Campbell, K.A., Sannazzaro, K., Rodgers, K.A., Herdianita., N.R., and Browne, P.R.L, 2004, Sedimentary Facies And Mineralogy Of The Late Pleistocene Umukuri Silica Sinter, Taupo Volcanic Zone, New Zealand, Journal Of Sedimentary Research, hal 727-746. 
Corbett, G.J. dan Leach, T.M., 1997, Southwest Pasific Rim Gold-Copper Systems: Structure Alteration And Mineralization. Short Course Manual. North Sydney.

Dipipo, R. 2008, Geothermal Power Plants, Edisi kedua, Dartmouth.

Fitriany, A.W., 2015, Alterasi Hdrotermal Pada Lapangan Panas Bumi Daerah Gunung Ringgit Provinsi Sumatera Selatan, Prosiding Pemaparan Hasil Penelitian Pusat Penelitian Geoteknologi LIPI Tahun 2014, Semarang.

Guibert, J.M. dan Park, C.F., 1986, The Ore of Ore Deposits, WaveLand Press, INC, Long Grove

Harahap, B.H., 2010 Ciri Geokimia Batuan Vulkaniklastika di Daerah Tanjung Balit, Sumatera Barat: Suatu Indikasi Kegiatan Magma pada Eosen, Jurnal Geologi Indonesia, Vol. 5, No. 2, hal 75-91

Henley, R.W. dan Ellis, A.J., 1983, Geothermal Systems, Ancient and Modern, Earth Science Reviews.

Herdianita, N.R., Brown, P.R.L., Rodges, K.A., dan Campbell, K.A.,2000, Mineralogical and Textural Changes Accompanying Ageing of Silica Sinter, Minerallium Deposita, Vol.35, No. 1, hal. 48-62.

Henwood, N.W., Campbell, K.A., Lynne, B.Y., Guido, D.M., Rowland, J.V., dan Browne, P.R.L., 2017, Snapsot of Hot-Spring Sinter at Geyser Valley, Wairekeu, New Zealand, Following Anthropogenic Drawdown of The Geothermal Reservoir, Geothermics, Vol. 68, Elsevier, hal. 94-114.

Horwell, C.J. Williamson, B.J. Liewellin, E.W. Damby, D.E. Le Blond, J.S., 2013, The Nature and Formation of Cristobalite at The Soufriere Hills Volcano, Montserrat: Implications for The Petrology and Stability of Silicic Lava Domes, Bulk Vulcano, Springer.

Inanda, D.Y., 2017. sKarakteristik Sinter Silika Pada Mata Air Panas Di Kabupaten Solok dan Kabupaten Solok Selatan, Prosiding Seminar Nasional Fisika Universitas Andalas 2017, Padang.

Kholid, M. dan Marpaung, H., 2011, Survei Megnetotelurik Daerah Panas Bumi Bukit Kili Gunung Talang, Kabupaten Solok, Sumatera Barat, Prosiding Hasil Kegiatan Pusat Sumber Daya Geologi Tahun 2011, KPP Bawah Permukaan.

Le Meitre, R. W. 2002. Igneous Rocks a Clasification and Glossary of Terms, Second Edition. Cambridge, New York.

Lynne, B.Y., dan Campbell, K.A., 2003, Morphologic And Mineralogic Transitions from OpalA to Opal-CT In Low-Temperature Siliceous Sinter Diagenesis, Tauopo Vulcanic Zone, New Zealand, Journal of Sedimentary Research, Vol. 74, No. 4, Hal. 561-579.

Lindgren, W., 1933, Mineral Deposits, McGraw-Hill Book Company, inc, New York dan London.

Munandar, A., Suhanto, E., Kusnadi, D., Idral, A., dan Solviah, M., 2003, Penyelidikan Terpadu Daerah Panas Bumi Gunung Talang Kabupaten Solok - Sumatera Barat, Kolakium Hasil Kegiatan Inventarisasi Sumber Daya Mineral - DIM, SUBDIT Panas Bumi.

Pirajno, F., 1992. Hydrothermal Mineral Deposits. Principles and Fundamental Concepts for the Exploration Geologist. New York. Springer - Verlag.

Suteja, R., Rosana, F.M., dan Hardiono, A., 2016, Alterasi dan Mineralisasi Daerha Gunung Buleud, Desa Garumukti, Kecamatan Pamulihan, Kabupaten Garut, Provinsi Jawa Barat, Bulletin of Contribution, Vol. 14, No. 2, Unpad, hal 127-140.

Thompson, A.J.B. dan Thompson, J.F.H., 1996, Atlas of Alteration A Field And Petrographic Guide To Hydrothermal Alteration Minerals, Mineral Deposots Division. Canada.

Vandani, C.P.K., Sari, I.W.A., Mulyaningsih, E., Utami, P., dan Yunis, Y., 2014, Studi Alterasi Hidrotermal Bawah Permukaan Di Lapangan Panas Bumi "Beta", Ambon Dengan Metode Petrografi, Prosiding Seminar Nasional Kebumian Ke-7, Yogyakarta. 